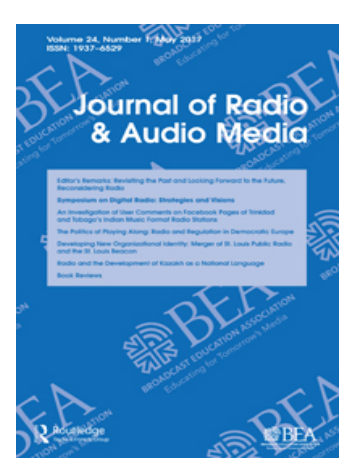

Journal of Radio \& Audio Media

\title{
The Politics of Playing Along: Radio and Regulation in Democratic Europe
}

\section{Elsa Costa e Silva \& Ana Isabel Reis}

To cite this article: Elsa Costa e Silva \& Ana Isabel Reis (2017) The Politics of Playing Along: Radio and Regulation in Democratic Europe, Journal of Radio \& Audio Media, 24:1, 130-143, DOI: 10.1080/19376529.2016.1239202

To link to this article: http://dx.doi.org/10.1080/19376529.2016.1239202

$$
\text { 曲 Published online: } 08 \text { May } 2017 .
$$

\begin{tabular}{l}
\hline Submit your article to this journal $\square$ \\
\hline View related articles $\square$ \\
\hline
\end{tabular}




\title{
The Politics of Playing Along: Radio and Regulation in Democratic Europe
}

\author{
Elsa Costa e Silva $\odot$ and Ana Isabel Reis
}

\begin{abstract}
The loss of localism has been a common trend in most radio markets in Europe and the United States. Deregulation of ownership led to a concentration phenomenon that has affected local radios in several western democracies. New forms of regulation have been considered as possible ways to stop the erosion of localism by applying rules to markets in the defense of diversity, pluralism, and the local dimension. This article analyses the local radio market in Portugal, by assessing the changes in the legislation and by examining the regulatory action that can, according to its remit, act preventively to avoid market forces to harm these principles.
\end{abstract}

\section{Introduction}

Local radio has been under several pressures in most democratic countries in the past decades. The 2007-08 financial crisis exacerbated the trends of economic difficulties and job losses in radio companies, but the consolidation of local markets, with the consequent downsizing, preceded the global wave of economic and financial breakdowns. Bearing a history of uneven development around the world (Buckley, 2000), radio has a pervasive and almost invisible nature that is a worldwide characteristic. Radio is believed to provide a medium of excellence to promote local public spheres (Crider, 2012), to deliver meaningful contributions to media diversity and democracy (Evens \& Paulussen, 2012), and to encourage local dialogues (Buckley, 2000).

Localism is a critical factor when analyzing the radio universe. Local content and ownership have been closely associated with the concept, a crucial rationale for justifying radio regulation and the close control of corporate operations taking place in the radio market. In democratic Europe, where state regulation is a current practice, though with different approaches, a more interventionist policy was a

Elsa Costa e Silva (Ph.D., University of Minho - Portugal) is a professor of Political Economy of Communication and of Journalism in the University of Minho. Her research interests focus on concentration of media ownership, media economics, regulation and new media.

Ana Isabel Reis (Ph.D., University of Porto - Portugal) is a professor of radio and journalism in the University of Porto in Portugal. Her research interest includes radio and the internet, in particular sound and radio journalism on the internet, the new digital platforms for radio production and radio history. 
traditional stance taken, mostly until the 1980s, in order to enhance media pluralism, defend localism, or prevent undue concentration (Freedman, 2008). Even in more market-driven contexts, like the United States, regulation has been central in the discourse of the FCC (Sauls \& Greer, 2007).

Despite a regulatory framework aimed at preserving diversity, the loss of localism has been the prevailing trend, especially since the 1990s. Deregulation of markets in western economies relaxed the limits on ownership, and the consolidation of media markets concentrated radio stations in the hands of fewer owners. Portugal was no exception, even though radio activity was kept under the control of the state as it continued to be an operation subject to a public license. The licensing process was de-politicized and is now run by a media regulatory agency, which analyzes and decides on each operation individually with the responsibility of safeguarding pluralism, diversity, and localism. Regulation has come to be seen as an outside force to markets that may force corporations to seek out and serve smaller audiences in the name of localism (Prindle, 2003). So, the question is: does the existence of regulation, in the form of a regulatory entity, control market forces in order to maintain localism in radio activity?

Looking at the particular case of the Portuguese radio marketplace, the aim of this discussion is to assess the effective role of regulation in the defense of localism in radio, by investigating:

a) How the concept of localism has evolved in the Portuguese legal framework and the effects of regulation, in terms of radio ownership, programming, and content.

b) Whether the existence of a strict regulatory mechanism to act a priori has resulted in a media sector oriented to values of pluralism, diversity, and localism (the aims of regulation) or in a market-oriented approach that has benefited radio group consolidation strategies.

This research is based on a document analysis of the main legislative acts that govern radio markets in Portugal, confronting the legal framework with the concept of localism, and also of the decisions of the media regulation agency. The approach of the analysis is one that not only considers, overt acts of regulation but also includes the effect of non-decision making (Freedman, 2010) which highlights the dynamics of power in the interplay between state and private media groups.

\section{Radio, Localism and Regulation}

Radio is a medium with a distinctive local character. Typically, radio stations are licensed to local communities, and the aims of broadcasting have long been concerned with servicing local communities in their needs and interests. For Croteau and Hoynes (2001), localism encompasses two elements: local control and local content. Following the work of these two authors, Starkey (2012) has presented a strong case in favor of localism in radio, arguing that locally owned radio stations are 
more prone to be sympathetic to the concerns of the community and more likely to promote local distinctiveness. Building on Habermas's configuration of the public sphere, Crider (2012, p. 242) has argued that "the public sphere, already diminished to an abstract form by mass media, cannot exist without an outlet for local publics to receive important local information." A genuine localism "demands comprehensive newscasts and plentiful public affairs programming" (Prindle, 2003, p. 317).

The mid-1980s saw important changes in media markets in general. Deregulation and market liberalization relaxed the rules on media ownership, allowing for concentration in most democratic countries in Europe, as well as the United States. Radio was not exempt from this transformation, which had a similar impact in the United States following the 1996 Telecommunications Act that opened up local markets to consolidation (Chambers, 2003; 2011; Polinsky, 2007; Saffran, 2011). From 1996 to 2002, the number of radio station owners in the United States dropped by $33.6 \%$ (Prindle, 2003). Also, in Europe, media markets were liberalized and private actors were allowed to invest, grow, and consolidate their positions. The loss of localism in local broadcasting, namely in the radio sector, has been closely linked to the deregulation of media markets in terms of ownership. Under the control of large groups, radio stations in the United States and in the United Kingdom, for instance, were subject to cost-cutting strategies, namely by replacing more expensive locally produced shows with syndicated programs (Crider, 2012; Starkey, 2012). Deregulation of radio markets, boosted by the 1996 Telecommunications Act, has led to a concentration of radio formats (Chambers, 2003), and this consolidation, which was "never seen before," was described as "fully impacting local coverage" (Sauls \& Greer, 2007, p. 39).

The most studied example of radio consolidation is the local radio market in the United States, but the phenomenon is not unique and has many examples in Europe. Though less documented, ownership concentration is a reality in diverse geographic contexts, such as Belgium (Evens \& Paulussen, 2012), the United Kingdom (Starkey, 2012), Spain (Arboledas \& Bonet, 2013) and Portugal (Silva, 2014). This consolidation has brought about important changes in programming as radio companies, seeking cheaper programming due to financial pressures, have increasingly been providing syndicated national shows (Crider, 2012).

The radio market in the United States is characterized by the predominance of large groups of radio stations, especially the most popular stations, and shows little ownership of a local nature (Chambers, 2011). Concentration of ownership has negatively impacted the diversity of formats (Chambers, 2003), and thus has resulted in an inadequate response of "local radio stations in meeting its obligation to serve local communities" (Saffran, 2011, p. 292). Starkey (2012), in reference to the context of the United Kingdom, points out that the local character of radio has been declining since the mid-90s and that, even if this distinctiveness may be more expensive when "compared to the relative cheapness of generic imaging and content, (but) the preservation of heritage-both cultural and radiophonic - may yet be worth considerable effort and expenditure as well as political will" (Starkey, 2012, 
p. 178). This political will, if it exists, can be expressed under strict rules for the safeguard of localism, namely by regulatory mechanisms.

Media regulation, assuming different configurations, is a widespread reality with a general aim to increase accountability towards society. The most common form is state regulation, in particular in the audiovisual sector. The audiovisual model of regulation, established since radio began regular broadcasts, is characterized by high levels of restriction, for reasons of a technical nature and to assure a balanced distribution of scarce resources (McQuail, 2003, p. 209). Primary forms of radio regulation are related to spectrum allocation (Aitken, 1994) and to the compensation due to the states for its use. With commercial radio, a new regulatory function arose for national authorities, that of securing effective competition within the available spectrum (Withers, 1999).

Besides addressing technical specificities, policy formation in the media sector is "generally guided by a notion of the "public interest,"' which democratic states are expected to pursue on behalf of their citizens (Cuilenburg \& McQuail, 2003, p. 182). This perspective of media regulation, mostly common in European democratic countries, is framed within some kind of interventionist approach that is comprised of active policies to highlight the importance of various political views and cultural values (Karpinnen, 2006), while the competition approach only considers government intervention to prevent or solve market failure (Evens \& Paulussen, 2012). Although this distinction presents a clear division between these two approaches, policy and regulatory actions of countries have been oscillating (not always coherently) between these two perspectives. Tension between intervention and non-intervention, as well as between different levels of intervention, has been central in policy action in most western countries (Freedman, 2010).

This tension has been more prominent in democratic Europe, being one of the rationales used to justify the existence of regulatory agencies. These "are the result of an ideological shift from social-democratic systems in Western Europe, and from communist regimes in Central and Eastern Europe, to free-market, neoliberal social arrangements which involved the deregulation of many areas of the economy, and society in general" (Jakubowicz, 2013, p. xii). Intended to protect institutions, these independent agencies have also been considered part of a shift in the governance of societies towards a more complex and diffuse process of decision and policy-making (Hamelink \& Nordenstreng, 2007). Regulatory entities have been set up in Europe to protect freedom of expression under the assumption that "they move the regulatory function out of the purview of the administrative hierarchy in support of the presumption of non-interference by the state" (Irion \& Radu, 2013, p. 18).

However, private actors have been quite reluctant in accepting State regulatory actions, particularly those that impact localism (Sauls, 2011, p. 315). This opposition from private media groups to any form of regulation may be one of the reasons "the majority of European countries have failed to create any political awareness of the social and cultural potential of local radio" (Evens \& Paulussen, 2012, p. 117), thus leading to a gap in terms of subsequent regulatory procedures and policies. Regulating the media is not only about what is done in terms of the legal and regulatory framework, but also a matter of what could have been done and was 
not. Freedman (2010) argues that any analysis of media regulation must account not only for the overt acts of regulation and policy, but also for the policy silence and the passive act of non-decision making, as a way to illuminate dynamics of power. Power, in this sense, "involves the capacity to mobilize one set of interests against another set of interests" (Freedman, 2010, p. 350).

\section{The Portuguese Radio System}

Portugal has a very distinctive radio system. From the mid-1970s, following the democratic revolution of 1974, a dualistic model offered citizens programming from a public station and from a private operator, owned by the Catholic Church. This situation persisted until the end of the 1980s, when thousands of pirate radio stations disrupted the spectrum and forced the authorities to act. Pirate stations, also called free radios, presented a very different way to interact with the audience, providing innovative playlists, and a new language of proximity, namely in terms of information and news (Bonixe, 2003). In order to legalize the situation, in 1988 the government launched a map of 402 local frequencies (to municipalities) and a licensing process, under a law known as the local radio law. From the following year on, the government authorized 312 local operators to broadcast. In 1990, two regional frequencies (one for the north of the country, another for the south) were licensed, thus completing the frame of radio activity in Portugal. But the process of licensing was considered to be political, rather than based on the soundness of the candidates' projects (Reis \& Nunes, 1994), and criticisms arose immediately, as the available advertising revenue to invest in radio was considered to be far too insufficient to accommodate the number of licenses granted. Many local radio stations indeed faced severe economic difficulties in the years to come (Santos, 2008), with stations closing down or having to join others in order to gain critical mass.

In the 90s, the phenomenon of local broadcasting was a consolidated reality in Portuguese media, even though some stations faced economic instability, and the rural zones of the country were not as well served as urban settings. At the same time, another significant development began to emerge: the establishment of retransmission chains of local broadcasters that, in some cases, meant colonization by stronger stations, and thus lead to a loss of their characteristic local distinctiveness (Reis \& Nunes, 1994). This practice was contested by the government and by some actors within the radio sector, but the attempts to regulate this situation were unable to stop the retransmission chains. In 2001, a new law was passed imposing obligations on operators in terms of providing local news (making it mandatory for stations to have three daily newscasts) in addition to their own programming. However, it did not prevent much of the retransmission practice. The debate continued at the beginning of the new millennium, also focusing on the weaknesses of local broadcasting, including market issues and financial sustainability.

Portugal currently has three major players in terms of radio, the first one being the state, within the public broadcasting service, with three national programming 
services (one with news and music for adults [Antena 1], another mainly musical station for teenagers and young adults [Antena 3], and another with classical music, [Antena 2]). The Catholic Church owns the RCOM group that has two national programming services (one $[R R]$ with news and music for adults and another, [RFM] mainly musical station for adults), and two other services with a national reach but broadcast through local frequencies (Radio Sim for the elderly and Mega FM for teenagers and young adults). Media Capital, a private group owned by the Spanish media group Prisa (also a major radio player in Spain with Cadena Ser), has a national programming service (Rádio Comercial) and four other programming services based on local frequencies with a reach that ranges from national (like M80 and Rádio Cidade) to metropolitan areas (like Vodafone FM or Smooth).

Another important player (mainly in terms of advertising investment) is the national news programming service TSF (belonging to Global Media, a national multimedia group), which transmits in a regional frequency in the North and uses local frequency in the center and south of the country.

Radio activity is regulated by the ERC (Entidade Reguladora para a Comunicação Social), the Portuguese media regulation agency. This regulator, which can be included in the trend of democratic Europe to set independent administrative bodies to regulate different sectors of economic activity (Tatcher, 2002), was created by law in 2005, with increased powers and a wider scope, namely in terms of sanctioning wrongdoings and in preventing concentration. Since launching new press services is free (only subject to registry), the ERC's scope of action includes mainly radio (by licensing and authorizing changes in programming) and television (by monitoring compliance of private broadcasters and public service with obligations in terms of entertainment and news services legally broadcast). It is also responsible for enforcing in all media the "right to reply" (a constitutional right to demand the rectification of any misinformation by the same medium in which it was published or broadcast). The rationale for the new architecture of media regulation was to increase its effectiveness, namely by consigning specific powers with respect to ownership and concentration, and to raise its legitimacy by stressing the independence of the body from governmental influence. Its council board is composed of five elements, four of them designed by the parliament (in a combined deal between the two main political parties). Law 53/2005 established that the ERC has to control the concentration of ownership of entities pursuing media activities when pluralism and diversity are at stake. However, Portugal has no pluralism or concentration law with a specific mechanism for setting limits to concentration, and the wording of the 53/2005 law is merely qualitative (see Silva, 2007). This limits the scope of the ERCs remit, as it is very unspecific, but in principle, it could also be transformed into an advantage if the council board was to assume a more comprehensive understanding of the legal possibilities. 


\section{The Portuguese Radio Market: Analysis of the Regulatory Action}

\section{Evaluating the Legal and Regulatory Context}

The current configuration of national radio groups is the result of changes in the legal framework that took place over the last 25 years, a period of time in which most media legislation was shaped after the Portuguese democratic revolution of 1974. In the particular case of radio, the legal framework has undergone significant changes in terms of the defense of localism, limits to concentration, and obligations to provide news outlets.

In the first radio law of the democratic regime, Law no. 87/88 (Lei no. 87/88, 30 Julho), passed in 1988, localism was very present. Operators, according to Article 6, were expressly obliged to meet the concerns, modes of expression, and cultural values of local communities, as well as to broadcast information of interest to the geographical range of the audience. In 2001, the new law (Lei no. 4/2001, de 23 de Fevereiro) shortened all these obligations to a simple formulation that only included programming targeted at the audience of the geographical space to which the license was given (Article 9). In 2010, another new law (Lei no. 54/2010, de 24 de Dezembro) was passed, and this formulation was maintained with two small but relevant changes: information was included in the programming obligations, but the specific allocation to the geographical context of the audience disappeared (Article 12). Audience is now a generic concept and not the group of listeners of a specific locality, which has obviously handicapped the localism reach of this law of a very relevant dimension. Another important change of this law which, again, cut off the close connection of radio to a local community is the fact that local stations are no longer obliged to have an establishment in the municipality to which the frequency was licensed. A physical presence is no longer required, and this is quite relevant in a context of syndicated programming, as it allows media groups to have only a centralized production center. Local contact is thus lost, and radio workers lack direct knowledge of local concerns and voices, which directly impacts their ability to share information of relevance with the audience of the geographical area of coverage. This is problematic considering that "locally produced content enable local citizens to access producers directly, so that content can better reflect local distinctiveness and cultural diversity, promote audience involvement in local discourse and thereby stimulate local participation and democracy" (Starkey, 2012, p. 168).

In terms of ownership, changes were always made in order to relax the limits, which has increased the possibility of concentration. Within the licensing process permitted by Law no. 87/88, ownership of broadcasters was limited to $30 \%$ of a second broadcaster (no. 5 of Article 2). But this significantly changed in the next legislative process: Law 4/ 2001 increased the number of operators under the same owner to five (Article 7). This change was a significant step forward for the establishment of radio groups. This law also sought to address the issue of retransmission-another de facto way to promote concentration, even though not under formal ownership agreements. The association 
between music or news programs subordinated to the same model was allowed to a limit of four operators (Article 30). For nearly a decade, this legal framework did not stop radio groups from growing, bypassing the legal restrictions by the use of intermediary organizations (Silva, 2004; Santos, 2005).

Again the legal framework had to adjust to the market reality, and another change in the law extended the possibilities of concentration. Law no. 54/2010 set the limit for licenses under the same owner at $10 \%$ of the total existing licenses (no. 3 of Article 4). This meant that the limits were extended from five to more than thirty licenses.

This is not, however, an automatic allowance to media groups. In fact, operations of ownership have to be individually authorized by the ERC. The current radio law, in its Article 4, establishes that the ERC may prohibit, through a binding decision, concentration operations that constitute "a risk to free expression and confrontation of differing points of view," when the previous regulator could only issue advisory opinions and had no jurisdiction over concentration of ownership. The ERC is also responsible, according to the law, for authorizing retransmissions of programming within a partnership agreement or by means of an association of broadcasters (Articles 10 and 11). The main difference between these two legal configurations is that the association, new in the legal radio framework, allows for a 24-hour retransmission, while the partnership only permits a maximum of 16 hours of retransmission. The maximum operators associated is limited to six broadcasters, but there is no limit to the number of partner operators, nor are these two legal figures mutually exclusive. This is why, for instance, a national station called M80, broadcast by the major radio group in Portugal (Media Capital), is retransmitted by one regional frequency and 18 local frequencies.

Another significant change brought about by the law was the possibility for operators to create thematic programming, which excuses them from meeting obligations in terms of the inclusion of Portuguese music in the playlists and of presenting three daily news services (Article 8). This means that thematic local broadcasters are no longer obliged to offer local news to their audiences, thus failing to accomplish one of the main elements of localism: local content. The combination of being a thematic radio station and broadcasting in association with a centralized production center is fatal to local news production. As stated by Crider (2012, p. 229), the fact that "programming decisions are made at corporate headquarters and passed down to the regional levels and eventually to the local markets" means that "this lack of control ultimately affects the amount of local control."

It is now clear that the trend in Portugal, in terms of the legal possibilities for radio activity, is the loss of localism, which was enhanced either by relaxation in terms of ownership, allowing for an increase in concentration, or by the loosening of obligations in terms of the broadcasting of local content. However, one thing is the legal possibility to consolidate (ownership and programming), another is the authorization to do so. Each operation has to be formally authorized by the ERC within the legal framework, and there is room to negotiate: operations aiming at the concentration of media companies can be prevented if there is a risk to freedom of speech or to the presentation of different points of view; the transformation into a thematic 
programming service should be authorized only after considering its potential impact on the diversity and pluralism of the programming on offer in the geographical coverage area, and on the local news.

The question now is how to assess the level of interference of the regulatory agency in the market dynamics in terms of safeguarding pluralism and localism, by evaluating how the ERC has used the mechanisms legally displayed to prevent consolidation of programming and ownership. Considering the policy analysis proposed by Freeman (2010), the act of non-decision-making and policy silences in the radio sector will be discussed in order to shed light on the dynamics of power and the interplay between the state and private players.

\section{Regulation in Action}

In a previous study of the ERC's decisions in relation to radio ownership and activity, Silva (2014) presents evidence that the Portuguese media regulator endorsed the increased concentration in radio broadcasting - in some cases, with formal ownership transfer, but in others just by authorizing an agreement between the central radio station and local companies. This second mechanism is very important in the period of analysis from 2008 to 2011, as there was, until the end of 2010, a very strict limitation on the concentration of ownership (up to five radio operators). The ERC issued 43 authorizations to retransmit centrally broadcast content on local frequencies, and the weight of national media groups in those transactions increased with the allowance of the regulator entity.

As we have seen, the new radio law of 2010 significantly altered the limits to concentration of ownership and to the association between operators for syndicated programming, and allowed operators to forego regular newscasts and local information. Since it was passed at the end of that year (December 24, 2010), it only produced effects, in terms of the legal framework, in 2011. This gives the period of 2011 and following years a particular scenario for the ERC to stress its positioning in face of the market's force. The ERC's website displays the processes and decisions adopted by the board, thus allowing for the monitoring of its decisions on the requirements presented by the media groups..

So, in order to evaluate how the ERC has used the mechanisms legally displayed to prevent consolidation of programming and ownership, the regulators' decisions from 2011 to 2014 were individually analyzed. In this period, the ERC issued 132 decisions (individual links are not listed as the number is too large, but can be retrieved from the ERC's site by a search of radio authorizations) specifically related to authorizations request to changes in ownership or programming of local frequencies. Considering that in Portugal there were, at the end of 2014 and according to the ERC, 323 local frequencies, this means that in that period the ERC evaluated requests related to $40 \%$ of the local radio universe in Portugal. 
Table 1

Processes Analyzed by ERC; Own Elaboration Based on Data Retrieved From ERC's Site

\begin{tabular}{llrrrr}
\hline & Authorizations Requested & 2011 & 2012 & 2013 & 2014 \\
\hline \multirow{5}{*}{ Ownership } & $\begin{array}{l}\text { Processes (one process can include more } \\
\quad \text { than one operation) }\end{array}$ & 23 & 26 & 49 & 17 \\
& Single Transaction & 2 & 10 & 11 & 6 \\
& Concentration & 14 & 5 & 18 & 3 \\
Programming & 1 & 4 & 16 & 5 \\
& Retransmission & 6 & 8 & 22 & 4 \\
\cline { 2 - 5 } & Thematic (only music, no local news) & & & & \\
\hline
\end{tabular}

Table 1 shows the distribution of authorization requests, organized by type of operation. It highlights the fact that radio owners were quite willing to act upon the new legal possibilities and that the consolidation of markets, either by ownership transactions or by syndicating programming, was pursued intensively.

Out of all requests submitted to the ERC, only eight were denied authorization. However, none of these denials had to do with the responsibility of the regulator to safeguard pluralism or localism. All the refusals were linked to technicalities: in seven cases (in 2011), the authorizations were denied because of legal impediments (the fact that new changes in programming or ownership could only occur two years after the last modification), and in another case, in 2014, the denial was due to a possible technical overlap of regional and local frequencies. The fact that the ERC was not acting upon any consideration for localism or pluralism is proved by the fact that the authorizations were granted when media owners presented the 2011 requests again (in 2013).

So, all the operations presented by the radio owners were authorized, thus highlighting that the ERC shadowed market forces at the expense of localism: by deciding positively on 40 ownership concentrations in the period, allowing for the growth of syndicated programming, and also by authorizing local operators to change to musical programming with no newscast obligations. In these kinds of operations, it is useful to note that the justifications presented by the regulator to decide on the requests were not coherent. In some cases, the change to musical programming was authorized because it would not affect the diversity of the offer, as other operators in the region had general programming. But when there was not any other operator with general programming, requests were nonetheless authorized on the grounds that local news could be provided by digital services, such as Web sites or newspapers. Even when the operator was the only one in the municipality, the ERC held that the change to thematic programming could enhance diversification of radio choices.

In terms of the distribution of the local frequencies targeted by the changes, the processes show a concentration in the coastal areas, conurbations and the two major metropolitan areas of the country (Lisbon and Porto), which indicates a clear 
indifference by the major media groups to the interior of the country and a focus on the areas providing larger audiences. Thus, while interior radio stations still tend to maintain a generalist type of programming and local news, more densely populated areas are less likely to have something similar.

Some operations were requested by small-scale radio groups (up to five operators normally in the same region and broadcasting in association) and by two median scale radio groups, that, curiously, did not follow a retransmission strategy. One is Música no Coração/Lusocanal, a radio group that is also a live entertainment company, and that controls 12 frequencies for 9 programming services, and the other is Global Difusion, a group linked to a religious movement started in Brazil, that directly controls 10 local frequencies and has arrangements for shared shows (with religious purposes).

Looking now at the biggest players in terms of the radio market, two groups (Rádio Renascença and Global Media) kept a low profile in the period of analysis. In fact, RR asked the ERC to analyze eight operations involving changes in ownership and programming, but involving only three operators. Global Media and the brand TSF bought two operators in the Portuguese offshore territory (Madeira and Azores) and linked a local frequency to its news programming. It tried, in 2014, to buy a local operator, but that operation was denied due to technicalities in the spectrum coverage.

The third big private player, the Media Capital group, was, on the contrary, very dynamic during the analysis period and was the one that took most advantage of the new law. Although it officially owns only one national frequency, one regional, and 16 local operators, the group controls up to 36 local frequencies to retransmit its five programming services. Besides the national service, Rádio Comercial, Media Capital has another station with national coverage (M80), two programmers reaching most of metropolitan and urban areas in Portugal (Cidade and Smooth), and another (Vodafone) that broadcasts to the two most important Portuguese cities. The year 2013 was particularly important for Media Capital. After having completed the twoyear window introduced by the law of 2010, the radio group launched a major organization of its radio outlet, nationally consolidating the M80 brand and establishing the brand Smooth.

Media Capital was the one that benefited the most from the legal changes, shutting down establishments all over the country associated with the local frequencies. Although it is a group with solid financial health, and thus one with more economic resources to supply and maintain structures to provide local news, it has been the most active in taking advantage of the legal figures of legal mechanisms, such as association and partnership, and changes to thematic stations, to escape obligations to provide newscasts and be locally present. Media Capital acquired the ownership of 13 more local operators, asked for retransmission of 17 stations (either with a partnership or in association) and for 19 changes from generalist to thematic programming. All were authorized. This means that about $40 \%$ of all the ERC's rulings during the analysis period regarding the radio market originated with Media Capital. 


\section{Conclusion}

In light of the proposed model of political action analysis of Freedman (2010), the policy silences of the ERC regarding localism resulted in a market structured according to the strategies of media groups. The ERC could have denied authorizations to the transformation of operators into thematic radio stations, especially in areas where no other option in terms of radio was available, considering that its role is to "safeguard an information component of local nature." The non-decision making attitude of the ERC is even more striking considering that, in a previous moment, the agency issued a document for public consultation on the promotion of information diversity in radio (ERC, 2012), thus showing its awareness to the problem. However, the document was not turned into regulation, and the intents of the regulator simply disappeared. Regulation can have a role in defending localism, and the law opened up this possibility, but the ERC was a willing partner to market forces. In the interplay between public interest and private strategies, the interests of the media group prevailed in a context where the legal frame was tailored to fulfill its needs, and the ERC just played along.

In fact, legal documents concerning the radio market evolved in Portugal in a way that favored the private interests and lead to the loss of localism: in owners and in content, especially news and information. Concentration of ownership and consolidation of programming services were increasingly permitted over the last 25 years, and the existence of a structured regulation entity that can act a priori did not prove to be enough in terms of setting a media sector oriented toward values of pluralism, diversity and localism - which is why regulation was said to exist in the first place. Considering the long-lasting difficulties of local radio, mainly due to insufficient advertising revenues, the regulator adopted a marketoriented approach that has benefited radio group consolidation strategies and cost-cutting measures.

The ERC's performance concerning the radio market may raise the question of how an independent regulatory body could be more willing to endorse the interests of major commercial players in the market, instead of defending legal requirements of pluralism, diversity and localism clearly formulated. First, there is a historical and political context to consider. In a country where concentration of ownership has always been positively considered in terms of political discourse (Sousa \& Silva, 2009; Silva, 2004), a mandate to defend pluralism and localism did not seem enough to lead the ERC to a more energetic defense of these principles in radio activity. Second, most civil society has not been mindful of the changes introduced in the market and, except for some concerns expressed by the Journalists' Union, no civic organization or movement has promoted any concerted action to create awareness of this issue. There has been no national debate on radio (even less about local radio) suggesting that this has been a mostly silent process driven by an economic rationale, at the expense of local diversity and cultural pluralism. 


\section{ORCID}

Elsa Costa e Silva (D) http://orcid.org/0000-0002-7215-6384

\section{References}

Aitken, H. G. (1994). Allocating the spectrum: The origins of radio regulation. Technology and Culture, 686-716.

Arboledas, L., \& Bonet, M. (2013). Radio on the Iberian Peninsula: Autarky, revolution and convergence. International Communication Gazette, 75, 205-224.

Bonixe, L. (2003). As rádios locais em Portugal: Informação e função social -Uma análise dos noticiários das rádios do distrito de Setúbal. Dissertação de Mestrado defendida na Universidade Nova de Lisboa.

Buckley, S. (2000). Radio's new horizons Democracy and popular communication in the digital age. International Journal of Cultural Studies, 3, 180-187.

Chambers, T. (2003). Radio programming diversity in the era of consolidation. Journal of Radio Studies, 10, 33-45.

Chambers, T. (2011). Local ownership and radio market structure. Journal of Radio \& Audio Media, 18, 263-280.

Crider, D. (2012). A public sphere in decline: The state of localism in talk radio. Journal of Broadcasting \& Electronic Media, 56, 225-244.

Croteau, D., \& Hoynes, W. (2001). The business of media: Corporate media and the public interest. Thousand Oaks, CA: Pine Forge Press.

Cuilenburg, J. van, \& McQuail, D. (2003). Media policy paradigm shifts: Towards a new communications policy paradigm. European Journal of Communication, 18, 181-207.

ERC. (2012). Deliberação 1/OUT-R/2012, accessible at http://www.erc.pt/download/ YToyOntzOjg6ImZpY2hlaXJvljtzOjM5OiJtZWRpYS9kZWNpc29lcy9vYmplY3RvX29mZmx pbmUvMTk4OC5wZGYiO3M6NjoidGlOdWxvljtzOjlyOijkZWxpYmVyYWNhby0xb3V0LXI yMDEyljt9/deliberacao-1 out-r2012.

Evens, T., \& Paulussen, S. (2012). Local radio in Europe: Policy options for a sustainable sector. Media, Culture \& Society, 34, 112-121.

Freedman, D. (2008). The politics of media policy. Cambridge/Malden, MA: Polity Press.

Freedman, D. (2010). Media policy silences: The hidden face of communications decision making. International Journal of Press/Politics, 15, 344-361.

Hamelink, C. J., \& Nordenstreng, K. (2007). Towards democratic media governance. In E. de Ben (Ed.), Media between culture and commerce (pp. 225-240). Bristol, UK: Intellect Books.

Hilliard, R. L., \& Keith, M .C. (2005). The quieted voice: The rise and demise of localism in American radio. Carbondale, IL: Southern Illinois Press.

Irion, K., \& Radu, R. (2013). Delegation to independent regulatory authorities in the media sector: a paradigm shift through the lens of regulatory theory. In W. Schultz, P. Valcke, \& K. Irion (Eds.), The independence of the media and its regulatory agencies. Bristol/Chicago, IL: Intellect.

Jakubowicz, K. (2013). Preface: Broadcasting regulatory authorities: Work in progress. In W. Schultz, P. Valcke, \& K. Irion (Eds.), The independence of the media and its regulatory agencies. Bristol/Chicago, IL: Intellect.

Karpinnen, K. (2006). Media diversity and the politics of criteria diversity assessment and technocratisation of European media policy. Nordicom Review, 27, 53-68.

McQuail, D. (2003). Teoria da Comunicação de Massas. Lisbon, Portugal: Fundação Calouste Gulbenkian.

Prindle, G. M. (2003). No competition: How radio consolidation has diminished diversity and sacrificed localism. Fordham Intellectual Property, Media and Entertainment Law Journal, 14, 279-325. 
Reis, A., \& Nunes, J. M. (1994). Os meios de comunicação social—breve síntese sobre a evolução dos media no período 87-94. In A. Reis (Coord), Portugal 20 anos de democracia. Lisbon, Portugal: Círculo de Leitores.

Saffran, M. J. (2011). Remarks on radio localism. Journal of Radio \& Audio Media, 18, 246-247.

Santos, R. (2005). Rádio em Portugal: Tendências e grupos de comunicação na actualidade. Comunicação e Sociedade-Economia Política dos Media, 7, 137-152.

Santos, R. (2008). Rádios locais em Portugal, 2000-2004. In M. Pinto \& S. Marinho (org.) Os media em Portugal nos primeiros cinco anos do século XXI. Porto, Portugal: Campo das Letras.

Sauls, S. J. (2011). Locally and free: What broadcast radio still provides. Journal of Radio \& Audio Media, 18, 309-318.

Sauls, S. J., \& Greer, D. (2007). Radio and localism: Has the FCC dropped the ball? Journal of Radio Studies, 14, 37-48.

Silva, E. C. (2004). Os donos da Notícia-A concentração da propriedade dos media em Portugal. Porto, Portugal: Porto Editora.

Silva, E. C. (2007). Concentração: os desafios à entidade reguladora da comunicação social. Comunicação e Sociedade, 11, 87-98.

Silva, E. C. (2014). Crisis, financialization and regulation: The case of media industries in Portugal. The Political Economy of Communication, 2, 47-60.

Sousa, H., \& Silva E. C. (2009). Keeping up appearances-Regulating media diversity in Portugal. International Communication Gazette, 71, 89-100.

Starkey, G. (2012). Live and local no more? Listening communities and globalising trends in the ownership and production of local radio. In M. Oliveira, P. Portela \& L. A. Santos (Eds.), Radio Evolution: ECREA Conference Proceedings (pp. 167-178). Braga, Portugal: Communication and Society Research Centre.

Tatcher, M. (2002). Delegation to independent regulatory agencies: Pressures, functions and contextual mediation. West European Politics, 25, 125-147.

Wall, T. (2000). Policy, pop, and the public: The discourse of regulation in British commercial radio. Journal of Radio Studies, 7, 180-195.

Withers, D. J. (1999). Radio spectrum management: management of the spectrum and regulation of radio services, (No. 45), IET. 